DIAJAR: Jurnal Pendidikan dan Pembelajaran
https://journal.yp3a.org/index.php/DIAJAR
ISSN Media Elektronik xxxx-xxxx
Vol. 1 No. 1 (Januari 2022) 10-16
DOI: xxxxx

\title{
Pembentukan Karakter Melalui Lagu Dolalan pada Mata Pelajaran Bahasa Jawa
}

\author{
Arif Muzayin Shofwan', Gandes Nurseto² \\ ${ }^{1,2}$ Program Studi Pendidikan Islam Anak Usia Dini, Fakultas Agama Islam, Universitas Nahdlatul Ulama, \\ Kota Blitar, Indonesia \\ Email: ${ }^{1}$ arifshofwan2@gmail.com, ${ }^{2}$ gandes.seta@gmail.com
}

\begin{tabular}{r} 
Informasi Artikel \\
\hline Diterima $: 04-12-2021$ \\
Revisi $: 18-12-2021$ \\
Diterbitkan $: 20-01-2022$ \\
Keywords: \\
\hline Character Building \\
Media \\
Dolanan Song \\
Javanese Language
\end{tabular}

\begin{abstract}
Character building in students can be done through a variety of subjects delivered by the teacher. This qualitative research using a case study describes the dolanan song in Javanese language subjects which is used to shape the character of students at MI Miftahul Huda Papungan 01 Blitar. The findings in this study, among others: First, the dolanan song functions as a medium to convey moral values to students, such as obedience to religious teachings, love for the homeland and nation, togetherness, cooperation, and others; Second, there are dolanan songs that contain educative value and vice versa, a teacher must choose dolanan songs that contain educational values for students; Third, several songs that can be found in this research, among others: Cublak-Cublak Suweng, Menthog-Menthog, Kidang Talun, Tikus Buntung, Gotri, and others; Fourth, most students feel happy and excited when singing the dolanan song because the song can be sung while playing (dolanan). Dolanan songs can also be used as an alternative to relieve tension in students when they are bored with thinking activities.
\end{abstract}

\begin{abstract}
Abstrak
Pembentukan karakter pada peserta didik dapat dilakukan melalui berbagai macam mata pelajaran yang disampaikan oleh guru. Penelitian kualitatif dengan menggunakan studi kasus ini mendiskripsikan tentang lagu dolanan pada mata pelajaran Bahasa Jawa yang digunakan untuk membentuk karakter siswa di MI Miftahul Huda Papungan 01 Blitar. Temuan dalam penelitian ini, antara lain: Pertama, lagu dolanan berfungsi sebagai media menyampaikan nilai-nilai moral kepada peserta didik, seperti: patuh kepada ajaran agama, cinta tanah air dan bangsa, kebersamaan, gotong-royong, dan lainnya; Kedua, lagu dolanan itu ada yang mengandung nilai edukatif dan sebaliknya, seorang guru harus memilihkan lagu dolanan yang mengandung nilai edukatif bagi peserta didik; Ketiga, beberapa lagu dolanan yang dapat ditemukan dalam penelitian ini, antara lain: Cublak-Cublak Suweng, Menthog-Menthog, Kidang Talun, Tikus Buntung, Gotri, dan lainnya; Keempat, kebanyakan siswa-siswi merasa senang dan gembira ketika menyanyikan lagu dolanan, sebab lagu tersebut bisa dinyanyikan sambil bermain (dolanan). Lagu dolanan juga bisa digunakan sebagai alternatif menghilangkan ketegangan dalam diri peserta didik manakala mereka jenuh dengan aktifitas berpikir.
\end{abstract}

Kata Kunci: Pembentukan Karakter, Media, Lagu Dolanan, dan Bahasa Jawa

\section{PENDAHULUAN}

Pembentukan karakter pada peserta didik dapat dilakukan dengan berbagai macam mata pelajaran. Salah satu cara membentuk karakter peserta didik adalah menggunakan lagu dolanan pada mata pelajaran Bahasa Jawa. Nadiroh menyatakan bahwa lagu dolanan adalah salah satu lagu yang biasa dinyanyikan anak-anak ketika bermain (dolanan). Pada jaman dahulu anak-anak bermain di halaman, baik 
waktu siang, sore, dan malam sambil melantunkan lagu dolanan. Ciri-ciri lagu dolanan adalah berbahasa sederhana, mudah dimengerti, lirik sedang, jumlah bait terbatas, biasa dilantunkan sambil bermain atau berjoget, dan isi lagu selaras dengan dunia anak-anak (Nadiroh, 2019: 2).

Sementara yang dimaksud pembentukan karakter (character building) adalah usaha terusmenerus seorang individu atau kelompok dengan berbagai cara untuk mengukir, mengembangkan atau melembagakan sifat-sifat kebajikan pada diri sendiri dan orang lain (Shofwan, 2021: 8). Berdasarkan pengertian tersebut dapat dijelaskan bahwa pembentukan karakter melalui lagu dolanan merupakan suatu usaha terus-menerus yang dilakukan individu atau kelompok untuk mengukir, mengembangkan atau melembagakan sifat-sifat kebajikan pada diri sendiri atau orang lain (peserta didik) melalui nilai-nilai yang ada dalam lagu dolanan.

Roffiq, dkk., menjelaskan bahwa lagu dolanan sarat dengan pendidikan moral dan sosial. Oleh karena itu, lagu dolanan sangat penting dikenalkan pada aak usia dini yaitu anak pra sekolah dan usia sekolah. Melalui lagu dolanan, anak dapat dibentuk karakter yang seutuhnya. Dalam lirik lagu dolanan, banyak bercerita tentang cinta kasih pada sesama, Tuhan, ayah dan ibu, keindahan alam, binatang - yang ditulis secara sederhana sesuai dan selaras usia anak-anak, serta menyiratkan makna kebersamaan, kemandirian, tanggungjawab, dan nilai-nilai sosial lainnya (Roffiq, dkk., 2017: 39).

Beberapa judul lagu dolanan yang terdapat dalam mata pelajaran Bahasa Jawa dan mengandung nilai-nilai pembentukan karakter individu dan sosial, antara lain: Gajah-Gajah, Gugur Gunung, Nyata Kowe Wasis, Buta-Buta Galak, Gundul Pacul, Jamuran, Padang Mbulan, Kidang Talun, Pitik Tukung, dan lain sebagainya. Anis, dkk., menyatakan bahwa melalui lagu dolanan semacam itu, anak dapat mengembangkan nilai kejujuran, keterbukaan, dan kearifan tertentu. Memahami arti dan makna yang terkandung dalam tembang dan lagu dolanan menjadi salah satu tujuan dalam mengajarkan pembentukan perilaku, sikap, dan karakter anak didik (Anis, 2019: 23).

Sementara itu, Shofwan mengatakan bahwa tujuan lagu dolanan pada mata pelajaran Bahasa Jawa adalah menanamkan budi pekerti seperti rasa hormat, kasih sayang, gotong-royong, tolongmenolong, kerukunan, ketentraman, kedamaian, cinta tanah air, dan semacamnya (Shofwan, 2021: 8). Dari sini tampak bahwa lagu dolanan pada mata pelajaran Bahasa Jawa dapat digunakan untuk membangun karakter bagi peserta didik.

Berdasarkan uraian di atas, tampak bahwa lagu dolanan pada mata pelajaran Bahasa Jawa juga digunakan sebagai salah satu media pembentukan karakter (character building) di MI Miftahul Huda Papungan 01 Blitar. Dengan demikian, penelitian ini akan mempertanyakan dua hal berikut, yaitu: (1) Bagaimana pembentukan karakter melalui lagu dolanan pada mata pelajaran Bahasa Jawa di MI Miftahul Huda Papungan 01 Blitar?; dan (2) Apa saja lagu dolanan pada mata pelajaran Bahasa Jawa yang digunakan untuk pembentukan karakter di MI Miftahul Huda Papungan 01 Blitar?.

Oleh karena pertanyaan mendasar di atas, maka penelitian ini memiliki tujuan sebagaimana berikut, yaitu: (1) mendiskripsikan pembentukan karakter melalui lagu dolanan pada mata pelajaran Bahasa Jawa di MI Miftahul Huda Papungan 01 Blitar; dan (2) mendiskripsikan berbagai lagu dolanan pada mata pelajaran Bahasa Jawa yang digunakan untuk pembentukan karakter di MI Miftahul Huda Papungan 01 Blitar. Berdasarkan tujuan tersebut diharapkan bahwa hasil penelitian ini akan berkontribusi bagi berbagai pihak untuk pembentukan karakter di lingkungan madrasah masing-masing.

\section{METODE PENELITIAN}

Tulisan ini merupakan penelitian kualitatif yang menurut Creswell (2014: 4) merupakan metodemetode untuk mengekplorasi dan memahami makna yang - oleh sejumlah individu atau kelompok - yang dianggap berasal dari masalah sosial atau kemanusiaan. Pengambilan data dalam penelitian ini dilakukan dengan mengumpulkan berbagai dokumen-dokumen tentang kurikulum Bahasa Jawa dari MI Miftahul Huda Papungan 01 Blitar mulai kelas I-IV. Baik kurikulum yang sudah terinci dalam silabus, RPP, prota atau promes. Tentu saja, pengumpulan data dengan cara wawancara dengan beberapa guru dan siswa juga dilakukan dalam penelitian ini.

Selain itu, penelitian ini menggunakan parsipatory research dalam proses pengumpulan data. Artinya, penulis secara langsung mengamati dan ikut serta dalam proses pelaksanaan pembelajaran dalam dan luar kelas di lingkungan madrasah. Penelitian ini dipandang sebagai penelitian kualitatif yang menurut Bogdan \& Biklen (1998: 4-7) memiliki lima karakteristik khusus, yaitu: (a). naturalistic atau naturalistic; (b). deskriptif atau descriptive; (c). perhatian pada proses atau concerns with procces; (d). 
induktif atau inductive; dan (e). perhatian pada makna atau meaning. Dengan demikian, penelitian ini akan berjalan alamiah, perhatian pada proses dan makna kemudian dideskripsikan secara induktif.

\section{HASIL DAN PEMBAHASAN}

Kartini (1999) menjelaskan bahwa lagu dolanan berbahasa Jawa merupakan sarana untuk bersenang-senang dalam mengisi waktu luang dan sebagai sarana komunikasi yang mengandung pesan mendidik. Lagu dolanan yang mengandung ajaran-ajaran dan nilai-nilai moral budi pekerti sangat menarik sebab sesuai dengan perkembangan dan jiwa anak-anak yang suka bermain-main. Apabila anak kurang atau tidak dibina pendidikan budi pekerti sedini mungkin, maka pada umur 14 tahun dia akan bisa mengembangkan sikap destruktif, cenderung ke arah brutal. Kurangnya pembinaan atau pendidikan budi pekerti dibuktikan banyaknya kejadian di usia remaja, dewasa, bahkan usia tua seperti halnya kenakalan remaja, tawuran masal, pelecehan seksual, dan semacamnya.

Berawal dari ungkapan di atas, maka hasil dan pembahasan pembentukan karakter (character building) melalui lagu dolanan pada mata pelajaran Bahasa Jawa di MI Miftahul Huda Papungan 01 Blitar dapat dideskripsikan sebagaimana berikut, antara lain:

Pertama, berbagai macam lagu dolanan yang digunakan sebagai media pembentukan karakter (character building) pada peserta didik di MI Miftahul Huda Papungan 01 Blitar dapat ditemukan pada mata pelajaran Bahasa Jawa kelas I-IV. Secara umum, pemanfaatan lagu dolanan sebagai media penyampai pesan telah berjalan berabad-abad dan dilakukan oleh para sesepuh Jawa. Bahkan pada jaman Islam, para waliyullah dalam Dewan Walisongo banyak menciptakan lagu dolanan dengan tujuan tersebut. Lagu dolanan yang sangat kental dengan nilai moral dan filosofi sudah terasa sangat penting untuk pembentukan karakter (character building) anak-anak. Di samping anak-anak senang memainkan dan melantunkan lagu dolanan semacam itu, mereka juga banyak mendapatkan hikmah-hikmah yang tersirat di dalamnya (Shofwan, 2021: 155).

Ilma Nurul Fajri menyatakan bahwa lagu dolanan penting sekali digunakan sebagai pembentukan karakter bagi peserta didik. Menurutnya, sebagaimana lagu dolanan Gundul Pacul memiliki nilai-nilai yang sangat luar biasa bahwa seseorang tidak boleh angkuh dan sombong. Orang sombong suatu saat pasti akan "ngglempang" atau terjatuh dengan sendirinya. Kalau sudah terjatuh, maka kesombongan tersebut akan diketahui merata di segala penjuru (segane dadi sak latar). Dari contoh lagu tersebut sudah jelas bahwa nilai-nilai (values) yang terdapat dalam lagu dolanan dapat digunakan untuk membentuk karakter bagi peserta didik (Wawancara Ilma Nurul Fajri, 18 Agustus 2021).

Tak jauh dari hal di atas, Sayyidah Mulin Nikmah menyatakan bahwa lagu dolanan berbahasa Jawa banyak sekali yang mengandung ajaran agama Islam. Misalnya, lagu dolanan berjudul Padhang Mbulan memiliki nilai yang sangat mendidik. Ungkapan "aja turu sore-sore" dalam lagu tersebut mengajak peserta didik agar tidak melakukan tidur di waktu sore hari, sebab waktu sore hari harus digunakan untuk mengaji Taman Pendidikan Al-Quran (TPQ) dan madrasah diniyah (madin) di masjid, mushalla, dan semacamnya. Selain itu, lagu dolanan Padhang Mbulan juga mengandung nilai kebersamaan untuk mensyukuri nikmat dan kuasa Tuhan Yang Maha Pemberi nikmat (Wawancara Sayyidah Mulin Nikamh, 21 Agustus 2021).

Ahmad Amir menyatakan bahwa lagu dolanan pada mata pelajaran Bahasa Jawa memiliki nilainilai luhur tradisi dan budaya nasional bangsa. Oleh karena itu, lagu dolanan dalam mata pelajaran Bahasa Jawa dapat digunakan untuk membentuk karakter cinta tanah air dan bangsa. Selain itu, banyak lagu dolanan yang memiliki nilai semangat untuk menuntut ilmu, beribadah kepada Allah, dan lain sebagainya. Biasanya, lagu dolanan semacam itu merupakan warisan dari para wali sebagai penyebar agama Islam (Wawancara Ahmad Amir, 23 Agustus 2021).

Sementara itu, Muhammad Imam Khudhori menyatakan bahwa dalam lagu dolanan berbahasa Jawa ada yang memiliki nilai edukatif dan sebaliknya. Oleh karena itu, seorang guru mata pelajaran Bahasa Jawa harus bisa memilih dan memilah lagu dolanan yang memiliki nilai edukatif. Contoh lagu dolanan yang tidak memiliki nilai edukatif adalah "Pring preketeg gunung gamping jegol. Kucing mlaku ngadeg kalajengking ngentup (.......)”. Titik-titik tersebut biasanya kemudian diisi dengan nama alat kelamin laki-laki dalam bahasa Jawa. Lagu dolanan berbahasa Jawa semacam itu harus dihindari oleh seorang guru, sebab tidak mengandung nilai edukatif bagi peserta didik (Wawancara Muhammad Imam Khudhori, 23 Agustus 2021). 
Lina Zunnuroin menyatakan bahwa lagu dolanan pada mata pelajaran Bahasa Jawa banyak mengandung semangat kebersamaan, gotong-royong, kerukunan, kemandirian, saling tolong-menolong, dan lain sebagainya. Lagu dolanan berbahasa Jawa dapat digunakan untuk membentuk watak dan budi pekerti yang baik. Namun yang paling banyak bahwa lagu dolanan itu memiliki nilai kebersamaan dan kerukunan. Walau lagu dolanan kadang tidak bisa ditangkap makna yang tersirat, tetapi tata cara melagukan lagu dolanan secara bersama-sama tersebut menunjukkan semangat kebersamaan dan kerukunan (Wawancara Lina Zunnuroin, 25 Aguastus 2021).

Berdasarkan hasil wawancara dengan guru-guru di MI Miftahul Huda Papungan 01 Blitar di atas dapat dinyatakan bahwa lagu dolanan pada mata pelajaran Bahasa Jawa memiliki fungsi sebagai media menyampaikan nilai-nilai moral kepada peserta didik, antara lain: tidak boleh sombong, patuh kepada ajaran agama, cinta tanah air dan bangsa, semangat kebersamaan, gotong-royong, kerukunan, kemandirian, saling tolong-menolong, dan lain sebagainya. Selain itu, dalam lagu dolanan ada yang mengandung nilai edukatif dan sebaliknya. Seorang guru harus mengajarkan lagu dolanan yang mengandung nilai edukatif kepada peserta didiknya dan menghindari lagu dolanan yang tidak mengandung nilai edukatif.

Kedua, berbagai macam lagu dolanan pada mata pelajaran Bahasa Jawa yang digunakan untuk pembentukan karakter di MI Miftahul Huda Papungan 01 Blitar dapat ditemukan dan dideskripsikan sebagaimana berikut. Lagu berjudul "Cublak-Cublak Suweng” dengan lirik lagu sebagaimana berikut; "Cublak-cublak suweng. Suwenge ting gerendel. Mambu ketudung gudel. Pak Empong lera-lere. Sopo ngguyu ndelikake. Sir, sir pong dele kopong. Sir, sir pong dele kopong” (Nurwati, 2019: 31-32).

Lagu dolanan berjudul "Menthog-Menthog" dengan lirik lagu sebagaimana berikut: "Menthogmenthog tak kandhani. Sak solahmu angisin-ngisini. Mbok ya aja ndeprok ana kandhang wae. Enak-enak ngorok ora nyambut gawe. Menthog-menthog mung lakumu. Megal-megol gawe guyu” (Ibid, 32).

Tak jauh dari itu, ada pula lagu dolanan berjudul "Kidang Talun" dengan lirik lagu sebagaima berikut: "Kidang talun. Mangan kacang talun. Mil kethemil mil kethemil. Si kidang mangan lembayung". Juga, lagu dolanan berjudul "Tikus Pithi" dengan lirik lagu sebagaimana berikut: "Tikus pithi. Nduwe anak siji. Cit cit cuwit, cit cit cuwit. Si tikus mangani pari”. Beberapa lagu dolanan lain, di antaranya: Tikus Buntung, Gotri, Bang Bang Tut, Gajah Belang, dan semacamnya (Ibid, 34).

Sementara itu, lagu dolanan berjudul "Gajah Belang” juga diajarkan pada mata pelajaran Bahasa Jawa di MI Miftahul Huda Papungan 01 dengan lirik lagu sebagaimana berikut: "Gajah belang. Saka tanah Plembang. Nuk regunuk, nuk regunuk. Gedhemu meh padha gunung” (Ibid, 35).

Ada pula lagu dolanan berjudul "Taman Sari” dengan lirik lagu sebagaimana berikut: "Iki taman sari. Tinanduran wit sarwasri. Ceplok piring manda kaki. Mawar menur lan melathi. Aja kok pethiki, aja kok undhuhi. Nyuda sri ning taman sari" (Ibid, 36).

Beberapa lagu dolanan lain adalah "Gajah-Gajah" dengan lirik lagu: "Gajah-gajah. Kowe tak kandhani jah. Mata kaya laron. Siyung loro kuping gedhe. Kathik nganggo tlale. Buntut cilik tansah kopat-kapit. Sikil kaya bumbung. Awak kaya lesung. Yen lumaku megal-megol” (Ibid, 38). Juga, ada lagu dolanan berjudul "Pitik Tukung" berikut: "Aku duwe pitik, pitik tukung. Saben dina tak pakani jagung. Petog gogok petog petog ngendog siji. Dak angkremake netes telu. Kabeh trondol-dol tanpa wulu. Megalmegol gawe guyu" (Ibid, 39).

Tampak pula lagu dolanan berjudul "Bulan Gedhe" berikut: "Bulan-bulan gedhe. Ana santri menek jambe. Ceblokna salining wae. Mumpung jembar kalangane. Mumpung gedhe rembulane. Suraka surak hiyo" (Ibid, 3). Begitu juga, lagu dolanan berjudul "Kupu Kuwi” berikut: "Kupu iku dak incupe. Mung aburmu ngewuhake. Ngalor ngidul ngetan bali ngulon. Mrana-mrene mung saparan-paran. Mbok yo menclok tak incupe. Mentas menclok cegreg. Nuli mabur bleber" (Ibid, 5). Ada pula lagu dolanan berjudul Gundul Pacul dan Kodhok Ngorek yang sudah familier di masyarakat desa telah diajarkan di MI Miftahul Huda Papungan 01 Blitar..

Selain itu, ada lagu dolanan berjudul "Lumbung Desa” berikut: "Lumbung desa pra tani padha makarya. Ayo dhi, njupuk pari nata lesung nyandak alu. Ayo yu, padha nutu yen wis rampung nuli adang. Ayo kang, dha tumandang yen wus mateng nuli madhang" (Ibid, 6). 
Beberapa lagu dolanan yang ditemukan pada mata pelajaran Bahasa Jawa kelas III berjudul "Padhang Mbulan" berikut: "Yo prakanca dolanan ing njaba. Padhang mbulan padhange kaya rina. Rembulane kang ngawe-awe. Ngelingake aja turu sore-sore" (Lestari, 2019: 23).

Berikutnya adalah lagu dolanan berjudul "Jaranan” yaitu: “Jaranan, jaranan, jarane, jaran teji. Sing numpak Mas Ngabehi. Sing ngiring para abdi. Jrek-jrek nong, jreg-jreg gung. Jrek, ejrek turut lurung. Gedebug krincing, gedebug krincing. Thok, thok, gedebug jedher. Gedebug krincing, gedebug krincing. Thok, thok, gedebug jedher" (Riyadi, 2019: 25). Selain itu, ada lagu dolanan berjudul "Jamuran" berikut: "Jamuran ya gege thok. Jamur apa ya gege thok. Jamur gajih bejijih sak ara-ara. Sira badhe jamur apa?" (Ibid, 25).

Adapun lagu dolanan yang ditemukan pada mata pelajaran Bahasa Jawa kelas IV berjudul "Ayo Ngudi Kapinteran" berikut: "Ayo kanca mumpung isih enom. Ngudi kapinteran sanguning urip. Aja nganti getun lan keduwung. Yen kebanjur getun nyambut gawe sarwa kidhung. Saben gegayuhan dadi wurung. Mburine sengsara batine nelangsa. Aja dadi gawe mring bebrayan. Prayogane tansah padha eling urip ing bebrayan. Becike ngudi luhuring kagunan ketrampilan. Aja sok kluyuran gayangan tanpa tujuan. Becik wigatekna pitungkasku. Sing penting mburine kelakon sedyane. Urip ayem tentrem lair batin" (Ibid, 7).

Selain itu, ada lagu dolanan berjudul "Gugur Gunung” berikut: "Ayo kanca, ayo kanca ngayahi karyaning praja. Kono-kene, kono-kene gugur gunung tandang gawe. Sayuk sayuk rukun bebarengan ro kancane. Lila lan legawa kanggo mulyaning negara. Siji loro telu papat maju papat-papat. Diulungulungake murih enggal rampunge. Holopis kuntul baris, holopis kuntul baris. Holopis kuntul baris, holopis kuntul baris" (Ibid, 7).

Terakhir adalah lagu dolanan berjudul "Buta-Buta Galak" berikut: "Buta buta galak, solahmu lunjak-lunjak. Ngadeg jingkrak-jingkrak, nyandak kuncung nuli tanjak. Bali ngadeg maneh, rupane ting celoneh. Iki buron apa dak sengguh buron kang remeh. La wong kowe-we-we-we, sing marah-marah. La wong kowe-we-we-we, sing marah-marah. Rupamu kok ngono. Hi, hi, aku wedi, ayo adhi padha bali. Kalo kae, kalo kae. Matane plerak-plerok, rok-rok-rok-rok. Kulite ambengkerok, rok-rok-rok-rok. Ya kulite ambengkerok" (Ibid, 9).

Ketika siswa-siswi MI Miftahul Huda Papungan 01 Blitar mendendangkan lagu dolanan pada mata pelajaran Bahasa Jawa, mereka tampak merasa senang dan gembira. Innaki Serena Aquila menyatakan bahwa dia merasa senang dengan lagu dolanan yang disampaikan oleh guru. Walau dia tidak mengetahui beberapa makna dan tujuan lagu dolanan, namun kebersamaan dan kekompakan menyanyikan lagu dolanan bersama kawan-kawan sekelas membuatnya merasa senang dan gembira (Wawancara Innaki Serena Aquila, 26 Agustus 2021). Pernyataan yang sama juga disampikan oleh beberapa siswa di kelas III, seperti Muhammad Abdul Halim, Muhammad Adzani Bagus, Nida Aufa Ardini, dan lainnya.

Sementara itu, Riska Isroatul Ahya menyatakan bahwa mata pelajaran yang paling disukai adalah ketika menyanyikan lagu dolanan bersama-sama. Banyak sekali lagu-lagu dolanan pada mata pelajaran Bahasa Jawa yang telah disampaikan oleh guru kepada kawan-kawan. Kawan-kawan selalu kompak ketika diajari menyanyi lagu-lagu dolanan, seperti Gundul Pacul, Bang Bang Tut, Jaranan, dan lainnya (Wawancara Riska Isroatul Ahya, 27 Agustus 2021). Pernyataan yang sama juga disampaikan beberapa siswa kelas IV, antara lain: Najwa Ainun Azizah, Dwi Nuryanto, Aqila Dzakiyah, Fahmi Bahtiar, dan lainnya.

Talita Nur Askanah menyatakan bahwa pembelajaran melalui lagu dolanan bisa membuat hati gembira. Sebab menyanyikan lagu dolanan biasanya dilakukan sambil bermain (dolanan). Semua kawan merasa senang dan bahagia. Contohnya ketika menyanyikan lagu Cublak-Cublak Suweng, semua kawan bisa merasa bahagia karena dinyanyikan sambil bermain. Dalam permainan berputar-putar tersebut, salah satu kawan mencari siapa yang menbawa batu dalam genggaman tangan yang kadang tidak mudah dicari dan ditebak (Wawancara Talita Nur Askanah, 31 Agustus 2021). Beberapa siswa di kelas V mengaggukkan kepala sebagai setuju dengan apa yang diungkapkan oleh Talita Nur Askanah tersebut.

Tak jauh dari hal di atas, M. Syahrul Al-Fatih menyatakan bahwa lagu dolanan pada mata pelajaran Bahasa Jawa sangat menyenangkan. Semua kawan telah diajari lagu dolanan oleh bapak dan ibu guru mulai kelas I hingga kelas VI. Menyanyikan lagu sambil bermain bisa menjadikan tambah semangat belajar. Biasanya, kawan-kawan ketika jenuh dengan mata pelajaran Bahasa Jawa yang memerlukan 
berfikir dalam, mereka lalu meminta kepada guru untuk menyanyikan lagu dolanan bersama-sama untuk menghilangkan ketegangan (Wawancara M. Syahrul Al-Fatih, 31 Agustus 2021). Beberapa siswa di kelas VI menganggukkan kepala sebagai tanda setuju pada apa yang disampaikan oleh M. Syahrul Al-Fatih tersebut.

Oleh karena pembahasan di atas, beberapa lagu dolanan pada mata pelajaran Bahasa Jawa yang digunakan untuk membangun karakter peserta didik di MI Miftahul Huda Papungan 01 mulai kelas I-VI dapat ditemukan sebagaimana berikut, antara lain: Cublak-Cublak Suweng, Menthog-Menthog, Kidang Talun, Tikus Buntung, Gotri, Bang Bang Tut, Gajah Belang, Taman Sari, Gajah-Gajah, Pitik Tukung, Bulan Gedhe, Kupu Kuwi, Gundul Pacul, Kodhok Ngorek, Lumbung Desa, Padhang Mbulan, Jaranan, Jamuran, Ayo Ngudi Kapinteran, Gugur Gunung, Buta-Buta Galak, dan beberapa lagu lainnya. Sementara itu, kebanyakan siswa-siswi merasa senang dan gembira saat menyanyikan lagu dolanan. Lagu dolanan bisa untuk menghilangkan ketegangan sebab dinyanyikan sambil bermain-main (dolanan) bersama.

\section{KESIMPULAN}

Berdasarkan hasil dan pembahasan di atas, dalam penelitian ini dapat diambil kesimpulan sebagaimana berikut: Pertama, lagu dolanan pada mata pelajaran Bahasa Jawa memiliki fungsi sebagai media menyampaikan nilai-nilai moral kepada peserta didik, antara lain: tidak boleh sombong, patuh kepada ajaran agama, cinta tanah air dan bangsa, semangat kebersamaan, gotong-royong, kerukunan, kemandirian, saling tolong-menolong, dan lain sebagainya; Kedua, dalam lagu dolanan ada yang mengandung nilai edukatif dan sebaliknya. Seorang guru harus mengajarkan lagu dolanan yang mengandung nilai edukatif dan menghindari lagu dolanan yang tidak mengandung nilai edukatif; Ketiga, beberapa lagu dolanan pada mata pelajaran Bahasa Jawa yang dapat ditemukan dalam penelitian ini, antara lain: Cublak-Cublak Suweng, Menthog-Menthog, Kidang Talun, Tikus Buntung, Gotri, Bang Bang Tut, Gajah Belang, Taman Sari, Gajah-Gajah, Pitik Tukung, Bulan Gedhe, Kupu Kuwi, Gundul Pacul, Kodhok Ngorek, Lumbung Desa, Padhang Mbulan, Jaranan, Jamuran, Ayo Ngudi Kapinteran, Gugur Gunung, Buta-Buta Galak, dan beberapa lagu lainnya; Keempat, kebanyakan siswa-siswi merasa senang dan gembira ketika menyanyikan lagu dolanan, sebab lagu tersebut bisa dinyanyikan sambil bermain (dolanan). Selain itu, lagu dolanan juga bisa dugunakan sebagai alternatif menghilangkan ketegangan dalam diri peserta didik manakala mereka jenuh dengan aktifitas berpikir.

\section{UCAPAN TERIMAKASIH}

Terima kasih tak terhingga disampaikan kepada kolega di Universitas Nahdlatul Ulama (UNU) Blitar yang selalu memotivasi dalam pengajaran, penelitian, dan pengabdian kepada masyarakat. Selain itu, terima kasih tanpa batas disampaikan kepada Pengelola Jurnal Diajar yang telah memberikan kesempatan untuk mempublikasikan atikel ini dengan penuh keterbukaan. Tak lupa, terima kasih disampaikan kepada Pengurus Yayasan Sayyid Hasan Nawawi (YASAHANA) Blitar yang telah banyak memberikan dukungan atas berlangsungnya penelitian ini. Mudah-mudahan Tuhan Yang Maha Kuasa selalu memberkahi semuanya di kehidupan kini dan mendatang.

\section{REFERENCES}

[1] A.M. Shofwan. Character Building Optimalisasi Pendidikan Karakter pada Anak Usia Dini. Sukabumi: Farha Pustaka, 2021.

[2] A.M. Shofwan. Pembelajaran Menggunakan Media Lagu. Surakarta: CV. Kekata Group, 2021.

[3] A.M. Shofwan. Seputar Lagu Dolanan untuk Anak Usia Dini. Jakarta: Penerbit Lini J-Maestro, 2021.

[4] A. Roffiq, dkk. "Media Musik dan Lagu pada Proses Pembelajaran” dalam Jurnal Pendidikan Dasar, Vol. 2, No. 2, September, 2017.

[5] D. Nurwati. Basa Jawa Untuk SD/MI Sederajat Kelas 1. Blitar: Samudra, 2019.

[6] H. Nadiroh. Bahasa Jawa Untuk SD/MI Sederajat Kelas 4. Blitar: Samudra, 2019.

[7] I. Riyadi. Gegladen Basa Jawa Kanggo Siswa SD/MI Kelas III. Blitar: Mitra Fokus, 2019.

[8] I. Riyadi. Gegladen Basa Jawa Kanggo Siswa SD/MI Kelas IV. Blitar: Mitra Fokus, 2019. 
[9] J.W. Creswell. Research Design Pendekatan Kualitatif, Kuantitatif, dan Mixel. terj. Ahmad Fawaid. Yogyakarta: Pustaka Pelajar, 2014.

[10] K. Lestari. Basa Jawa Untuk SD/MI Sederajat Kelas 3. Blitar: Samudra, 2019.

[11] R.C. Bogdan \& Sari Knopp Biklen. Qualitative Research for Education: An Introduction to Theory and Methods. London: Allyn and Bacon, 1998.

[12] S.F. Anis. “Analisis Nilai Moral lagu Daerah dalam Membentuk Kedisiplinan Siswa Dongeng”, Jurnal Lensa Pendas, Vol. 4, No. 1, Februari, 2019.

[13] Y. Kartini, wawancara Dr. Suharko Kasaran (Ketua Komisi Nasional Budi Pekerti) di Buletin Siang RCTI, 11 Mei 1999. 